\title{
ФОРМИРОВАНИЕ ТЕОРЕТИЧЕСКОГО ПРЕДСТАВЛЕНИЯ О ПРИНЦИПАХ ПРЕЕМСТВЕННОСТИ В ОБРАЗОВАНИИ ${ }^{1}$
}

Тюнников Ю.С.

Принцип преемственности занимает, пожалуй, центральное место в теории и практике непрерывного образования. Неслучайно на протяжении последних лет ему посвящено немалое количество исследовательских работ [1-5 и др.]. Однако, если оценивать разработанность методологического содержания и инструментального обеспечения принципа, то она по-прежнему остается невысокой.

Важно с самого начала понять, почему задача обоснования методологического содержания принципа преемственности не решена до сих пор. На наш взгляд, суть дела заключается главным образом в той позиции, которую исследователи занимают по отношению к самому принципу как объекту разработки. Для исследователя принцип преемственности выступает чаще всего как некоторый набор аксиоматических положений педагогической науки, как нечто само собой разумеющееся и не подлежащее сомнению. Задача, которую исследователь обычно ставит перед собой, состоит лишь в том, чтобы обосновать принцип какими-то дополнительными аргументами. Но это значит, что, пытаясь решать методологические вопросы, исследователь фактически остается в рамках педагогической аксиоматики, а не становится на собственную методологическую точку зрения. Чтобы правильно поставить вопрос о методологическом содержании принципа преемственности, необходимо, прежде всего, исследовать логику, механизмы и условия самой преемственность как специальной и самостоятельной области педагогического регулирования. Причем сделает это нужно в определенных ракурсах и измерениях.

Изучение преемственности как сложного и многопланового педагогического явления с неизбежностью предполагает разговор о сходстве и различие ступеней образования. Очевидно, мы можем их сравнивать и рассуждать о большей или меньшей степени адекватности по отношению друг к другу и в целом по отношению к социокультурной действительности только с применением вполне определенных критериальных характеристик и параметров. Важные дидактические особенности преемственности образования, на наш взгляд, отражают такие характеристики, как сопряженность, последовательность и соизмеримость.

Сопряженность образования это дидактическая характеристика, которая фиксирует сходство и различие содержания образования на разных его ступенях.

Последовательность это дидактическая характеристика ступеней образования, устанавливающая логику развертывания образовательного

\footnotetext{
${ }^{1}$ Работа выполнена в рамках государственного задания ФГБНУ «Институт стратегии развития образования Российской академии образования» (Проект № 27.8472.2017/БЧ).
} 
процесса с опорой на определенные учебные элементы и структуры познавательной деятельности.

Соизмеримость образования это дидактическая характеристика смежных ступеней образования, устанавливающая их сходство и различие по объему, плотности и сложности учебной информации, характеру и темпу производимых учебно-познавательных действий.

Ступени образования могут быть сопряженными и последовательными и в тоже время быть не соизмеримыми по сложности изучаемого материала. Или же преемственность смежных ступеней образования может быть обеспечена в части сопряженности и соизмеримости содержания, но не отвечать основным требованиям последовательного развертывания данного содержания.

Из всего этого следует вывод о том, что для решения задач построения и реализации преемственности в образовательной практике должны применяться не только определенные дидактические характеристики, но и специально разработанные критерии.

В многоуровневом образовательном процессе фактически на каждой ступени образования обнаруживаются периоды, имеющие разную качественную определенность. На одном из них возникают барьеры, которые вызывают у обучающихся наибольшие затруднения. Как правило, это происходит в адаптационный период, когда обучающиеся оказываются в новых условиях образования. Нередко именно в этом период между ступенями образования возникают разрывы учебно-познавательного, коммуникативного, организационного и иного характера, что требует со стороны педагогов особого внимания и хорошо скоординированных дополнительных усилий. После адаптационного периода следует стазис, иначе говоря, период стабильного, устойчивого состояния образовательного процесса, когда обучающиеся успешно преодолевают возникающие барьеры и осваивают нормативный набор образовательных задач. Временные границы начала ступени образования и начала стазиса могут не совпадать. Обычно это и наблюдается на практике. Что же касается завершения степени образования и стазиса, то по времени они совпадают полностью.

Переход от одного устойчивого состояния к другому (межстазисный переход) зарождается в недрах стабильного состояния одной ступени образования, а его завершение фактически означает начало стабильного состояния на другой ступени образования. На следующей ступени образования картина повторяется полностью или с некоторыми вариациями в части продолжительности стазиса и продолжительности межстазисного перехода.

Как видим, образовательный процесс, построенный на принципах ступенчатой организации, предстает в виде последовательности стазисов отдельных ступеней образования, которые чередуются с межстазисными переходами. Стало быть, преемственность в ее методологическом значении должна быть сосредоточена на межстазисной взаимосвязи ступеней образования (МС-взаимосвязь) и, соответственно, на тех условиях, способах и средствах, которые обеспечивают ее разработку и реализацию. 
Получается, что на повестку дня проблема преемственности ставится как проблема МС-взаимосвязи, которая предстает в характеристиках и критериях сопряженности, последовательности и соизмеримости. При этом сопряженность, последовательность и соизмеримость МС-взаимосвязи должна рассматриваться как в целом относительно ступеней образования, так и дифференцировано, то есть по отдельным направлениям образовательного процесса (познавательному, мировоззренческому, коммуникативному и др.).

Качественная определенность стазисов ступеней образования и межстазисных переходов закономерно связана с изменением в системе взаимодействия процесса личностного развития и образовательного процесса. Каждый раз при переходе на следующую ступень образования и формировании стазиса нового уровня система взаимодействия указанных процессов существенно перестраивается. В ней появляются новые элементы и структуры, устанавливаются новые связи. Тем самым, особенности взаимодействия между процессом личностного развития и образовательным процессом позволяют объяснить причины стабильности и нарушения преемственности образования.

Иначе говоря, для раскрытия сути преемственности в образовании необходимо, но недостаточно зафиксировать наличие устойчивых состояний образования и переходов между ними. Это понимание следует дополнить идеей о перестройке системы взаимодействия процесса личностного развития и образовательного процесса по мере продвижения обучающихся по ступеням образования. Тем самым в трактовке преемственности образования принципиальный акцент делается на взаимной импликации этих базовых процессов как главном механизме педагогического регулирования МCвзаимосвязи.

Сказанное позволяет заключить, что МС-взаимосвязи следует разрабатывать и реализовывать в нескольких ключевых аспектах и отношениях.

Прежде всего, необходимо определить условия, проблемы и противоречия межстазисного перехода, поскольку именно из них органично выводятся конкретные значения характеристик и параметров МС-взаимосвязи.

Особенности МС-перехода (условия, проблемы, противоречия) отражают следующие характеристики:

- мощзость MC-перехода (характеристика показывает степень преобразования образовательного процесса как системы: системноструктурный, частично-структурный, локально-структурный);

- тип MC-перехода (характеристика показывает, какого рода преобразования (события, процессы, процедуры) меняют исходное состояние педагогической системы и обеспечивают ее переход в новое качество; типы когнитивный, деятельностный, поведенческий (функционально-ролевой), коммуникативный, средовый, организационный);

- ширина MC-перехода (характеристика показывает, по каким основным направлениям осуществляется переход: целе-функциональный, содержательный, инструментально-технологический, организационный); 
- продолжительность MC-перехода (характеристика фиксирует время, отводимое на переход в целом и по каждому отдельно взятому направлению);

- интенсивность MC-перехода (характеристика выражает отнесенность ширины межстазисного перехода к его продолжительности).

Соответственно, значимыми характеристиками МС-взаимосвязи становятся:

- иенностно-смысловые ориентиры МС-взаимосвязи;

-барьеры MC-взаимосвязи (характеристика фиксирует те трудности и препятствия, которые возникают у субъектов образовательного процесса (педагогов и обучающихся) при переходе на следующую ступень образования);

-логико-содержательная основа МС-взаимосвязи (исходное содержание и логика его развертывания, на которые МС-взаимосвязь опирается или которые она моделирует посредством своих процедур и средств);

- уровень MC-взаимосвязи (характеристика показывает, как изменяется качество образовательного процесса в зависимости от количества, плотности и масштаба связей);

- продолжительность $M C$-взаимосвязи (характеристика фиксирует время, отводимое на реализацию МС-взаимосвязи в целом и по каждому направлению перехода).

Здесь необходимо сделать одно, на наш взгляд, весьма важное замечание. Принцип преемственности, имеющий общепедагогический статус для всей системы современного образования, затрагивает разные стороны образовательного процесса. Иначе говоря, он многофункционален. Поэтому правильно будет вести речь не об одном принципе, а об их некоторой совокупности.

Вкратце остановимся на группировании принципов преемственности, то есть на определении их состава по функциональной направленности. Принципы призваны обслуживать те практические задачи, которые ставятся и решаются педагогами в процессе педагогической регуляции преемственности образования. Основные задачи профессиональной деятельности педагогов в этой области следует разделить на три группы.

Задачи первой группы связаны с разработкой МС-взаимосвязи применительно к конкретным условиям перехода обучающихся на следующую ступень образования. Принципы этой группы непосредственно регулируют процедуры моделирования и конструирования МС-взаимосвязи и, следовательно, являются проектными.

Задачи второй группы направлены на создание необходимых условий для реализации МС-взаимосвязи на практике. Принципы этой группы процессные, поскольку они регулируют с привлечением разнообразного инструментария процессы функционирования МС-взаимосвязи.

Задачи третьей группы обеспечивают создание необходимой для МСвзаимосвязи организационной инфраструктуры. Эти задачи опираются на организационные принципы преемственности, которые задают 
методологические ориентиры при создании необходимых для МС-взаимосвязи ресурсов и организационных условий.

Методологическое содержание принципов преемственности связано с их структурой. Для того чтобы определить структуру принципов нужно ответить на вопросы: зачем они нужны, как и за счет чего они обеспечивают регуляцию преемственности образования.

Прежде всего, они должны содержать указание, для чего они предназначены. Такое указание дает структурный элемент - функции принuииа.

Принципы также должны давать необходимые представления о МСвзаимосвязи. Прежде всего, они должны показывать с опорой на какие элементы и объекты она устанавливается и реализуется. Данный структурный элемент принципа - квалификаторы.

Процедуры педагогической регуляции должны опираться на критериальные ограничители, которые задают определенные рамки и требования относительно разработки, функционирования и организационной поддержки МС-взаимовязи. Соответственно, в структуре принципов нужно выделить в качестве самостоятельного элемента критерии.

И, наконец, принципы должны предписывать определенные действия в некоторой логике их выполнения. Другими словами, задавать под конкретную задачу последовательность действий, которой следует придерживаться при разработке, функциональном обеспечении и организационной поддержке МСвзаимосвязи. Данные процедуры, по своей сути, являются алгоритмами и, соответственно, определяют важный структурный элемент принципов преемственности.

В завершение можно заключить, что представленные аспекты преемственности образования с ее теоретико-методологическими центрациями на МС-взаимосвязи открывают достаточно ясную перспективу для дальнейшей работы по обоснованию предметного и методологического содержания принципов преемственности.

\section{Литература}

1. Ахмадиева Ж.К.Теоретические основы преемственности дошкольного и начального образования. // Вестник КАСУ. 2012. №1. С.8-14.

2. Лаптева Н.В. Принцип преемственности в системе непрерывного образования. //Вестник СамГУ. 2010. № 7 (81). С.111-115.

3. Мачулис В.В. Роль новых информационных технологий в обеспечении преемственности естественнонаучного образования в средней и высшей школе: дис. ... канд. пед. наук. - Тюмень, 2002. 137 с.

4. Овчаренко Е.Н. Компонентный состав общепедагогического принципа преемственности обучения в системе «школа-вуз» // Научно-методический электронный журнал «Концепт». 2016. Т. 23. С. 64-67.

5. Филатова Л.О. Развитие преемственности школьного и вузовского образования в условиях профильного обучения в старшем звене средней школы. - М.: Лаборатория базовых знаний, 2005. 192 с. 